\title{
The Masculinisation of Old Age in South Asia
}

\section{Sehar Ezdi}

\begin{abstract}
This paper shows that the universal female survival advantage evades all the countries of South Asia, except Sri Lanka. Consequently, contrary to the global trend, these countries have more older men than older women in their populations. In view of this, the paper first develops a theoretical model (using the life-course perspective) to explain the mechanisms behind the possible persistence of this female deficit, i.e. the (older) missing women phenomenon, and highlights why this model may apply to South Asian countries. This discussion addresses the higher mortality of females' compared to males at each stage of the life course that culminate in old age (the life-course effect), the role of conflict and natural disasters that affect female mortality more adversely than male mortality (cohort effects), or a combination of the two. Subsequently, the paper calculates the extent of the female deficit in South Asian countries. The results of the calculation accord with the theoretical discussion by allowing the classification of the older missing women phenomenon as a life-course effect in some countries (e.g. India), a cohort effect in other countries (e.g. Nepal), and a combination of the two in specific countries (e.g. Pakistan).
\end{abstract}

Keywords: older missing women, female deficit, life-course

Ezdi, Sehar. 2021. The Masculinisation of Old Age in South Asia. Gender a výzkum / Gender and Research 22 (1): 78-107, http://dx.doi.org/10.13060/gav.2021.014.

The female survival advantage, as measured by higher female vis-a-vis male life expectancy persists across all countries worldwide (Barford et al. 2006). This would suggest that the number of women exceeds the number of men (Hazzard, Bowden 1990). The population estimates in Table 1 provide evidence of this fact. Table 1 calculates the sex ratios (male/female) for the world and different regions therein to show that regardless of the level of development, the number of women exceeds the number of men in the 60+ population in all regions of the world, and this excess of women becomes more pronounced as the population ages (i.e. from $60+$ to $80+$ ). 
Table 1: Sex ratios (male/female) for world regions in 2015

\begin{tabular}{|l|l|l|}
\hline Region/country & $\mathbf{6 0 +}$ & $\mathbf{8 0 +}$ \\
\hline World & 0.86 & 0.63 \\
\hline More developed regions & 0.77 & 0.55 \\
\hline Less developed regions & 0.90 & 0.71 \\
\hline Least developed regions & 0.88 & 0.81 \\
\hline
\end{tabular}

Source: United Nations Department of Economic and Social Affairs (2017), author's calculations.

The ratios in Table 1 translate into women accounting for $54 \%$ of the world population aged $60+$ and $61 \%$ of the population aged $80+$ in 2015 (UNDESA 2015a). By 2050, the comparative estimates are projected to be $53 \%$ and $58 \%$ (UNDESA 2015a), respectively, with the lower percentages resulting from male gains in life expectancy in developed countries (UNDESA 2015a). Nevertheless, the female advantage at older ages until 2050 is substantial enough for some authors to dub it the feminisation of later age on a global level (e.g. Davidson, DiGiacomo, McGrath 2011), both in developed countries (e.g. Peace et al. 2007) and in developing countries (e.g. UN-INSTRAW 1999).

However, this seemingly universal phenomenon appears to evade some countries, i.e. in some countries the number of older men exceeds the number of older women despite the female advantage in life expectancy, creating a contradiction between life expectancy and female preponderance in old age. Table 2 uses the example of South Asia to shed further light on this.

Table 2: Sex ratios (male/female) and life expectancy (female-male) for South Asian countries in 2015

\begin{tabular}{|l|c|c|c|}
\hline Region/country & L.E. gap & S.R. $\mathbf{6 0 +}$ & S.R. 80+ \\
\hline World & 4.56 & 0.86 & 0.63 \\
\hline Asia & 3.84 & 0.95 & 0.70 \\
\hline South Asia & 2.85 & 0.97 & 0.86 \\
\hline Afghanistan & 2.47 & 0.92 & 0.77 \\
\hline Bangladesh & 3.13 & 1.02 & 0.93 \\
\hline Bhutan & 0.27 & 1.21 & 1.11 \\
\hline India & 2.85 & 0.95 & 0.82 \\
\hline Iran & 2.24 & 1.04 & 1.10 \\
\hline Maldives & 2.06 & 1.07 & 1.35 \\
\hline Nepal & 3.04 & 0.88 & 0.75 \\
\hline Pakistan & 1.85 & 1.04 & 1.10 \\
\hline Sri Lanka & 6.79 & 0.80 & 0.67 \\
\hline
\end{tabular}

Source: United Nations Department of Economic and Social Affairs (2017), author's calculations. 
Table 2 illustrates that the preponderance of women observed in Table 1 is either non-existent or less noticeable in all the countries of South Asia except Sri Lanka. In Bhutan, Iran, Maldives, and Pakistan, it is clear that the pattern is reversed for both older categories: Not only is there a preponderance of men in the older population but also this preponderance increases as the population ages (i.e. from $60+$ to $80+$ ). In Bangladesh, the number of older men exceeds the number of older women in the 60+ category, with the trend reversing in the $80+$ category while still remaining well above the world average. In Afghanistan, India, and (to a lesser extent) Nepal, this general trend of a reduction in the share of men as the population ages is evident; however, the proportion of women in the older population is far below the average for the world or less developed countries. This contradiction between the gender gap in life expectancy and the female deficit in old age (i.e. older missing women) entreats an explanation.

Over two decades ago Amartya Sen $(1990,1992)$ introduced the term 'missing women' to refer to the number of women who should be alive at a given point of observation but are not. He estimated that in the 1990s more than 100 million women were missing in parts of Asia and Africa (Sen 1990). Since then several authors have attempted to refine the methodology used to calculate the number of missing women (e.g. Coale 1991; Klasen 1994), update the number of missing women (e.g. Klasen, Wink 2003; Bongaarts, Guilmoto 2015), identify the causes (e.g. Park, Cho 1995; Das Gupta, Shuzhuo 1999) and the consequences (e.g. Hudson, Den Boer 2005; Ebenstein, Sharygin 2009) of missing women, outline future policy implications that might overcome the problem of missing women (e.g. Chung, Das Gupta 2007), and even calculate the expected number of missing women in the future (e.g. Attané 2006). However, the majority of studies that attempt to explain the phenomenon do so at the time of birth and early childhood, with only a few recent studies addressing the phenomenon in adulthood. These studies focus on Asia (e.g. Guilmoto 2009) and Africa (Bongaarts, Guilmoto 2015) at a broader regional level or emphasize specific countries in East and Southeast Asia (e.g. China; Zhu, Lu, Hesketh 2009) and India (e.g. Das Gupta, Mari Bhat 1997). There are only four papers to date that address the existence of the phenomenon in the older (60+) population. The first paper, Anderson, Ray (2010), restricts its analysis of the missing women phenomenon by age group to three regions: China, India, and Sub-Saharan Africa. The second paper, Anderson, Ray (2012), addresses the age distribution of the female deficit across different states in India. The third paper, Bongaarts, Guilmoto (2015), shows the persistence of missing women in the older population on a global level. The final paper, Ezdi, Künemund (2019) shows that the brunt of the missing women phenomenon is moving from younger to older age categories in the Middle Eastern countries of Asia and East and Southeast Asia, and is more heavily concentrated in the former rather than latter set of countries. 
In light of Sen's writings, subsequent literature and the relatively recent demographic transformation of South Asian countries (Véron 2008), the deficit of women at an older age (as presented in Table 2) should come as no surprise, as it is continuous and contingent upon a lifetime of cumulative disadvantages, and it would be (and to some extent already has been) revealed by a comparative analysis of younger and middle-aged men and women (Gibson 1996). Furthermore, the disadvantaged position of older women in society is well established because of their vulnerability across multiple domains throughout the life course, especially in old age (Davidson, DiGiacomo, McGrath 2011; Bennett, Zaidi 2016).

The discussion to this point makes it evident that while literature documents the persistence of an (older) missing women phenomenon and female vulnerability in old age, it fails to provide not only a concrete explanation for the mechanism that perpetuates the older missing women phenomenon, but also an explanation of the factors that generate cross-national variability in the (older) missing women phenomenon. This paper addresses these concerns by: (1) providing a theoretical foundation for the persistence and cross-national variation of the (older) missing women phenomenon; (2) using data from UNDESA (2017) and the example of South Asia to depict the practical applicability of this theoretical framework. The paper is organised as follows: the second section presents the theoretical foundation of the analysis; the third section discusses the data and methodology; the fourth section describes the results of the South Asian example; the fifth section provides an analysis and discussion of the results; and the sixth section concludes the paper.

\section{Theoretical foundation}

The (older) missing women phenomenon is based on three theoretical premises: First, being female generates inequalities at each life stage that either lead to premature mortality at that life stage or accumulate into a higher mortality risk for women at subsequent life stages (Ferraro, Shippee 2009). Second, the inequalities (and cumulative disadvantage) faced by women may differ by birth cohort (Ryder 1965) or by cohort and/or period effects (Mayer 2004). Third, the inequalities/cumulative disadvantages faced by women and birth cohorts may vary at the cross-national level (Settersten, Mayer 1997; Mayer 2004). Figure 1 depicts how these premises amalgamate within the life-course framework to precipitate the (older) missing women phenomenon at each life stage and in the population as a whole.

The analysis starts at the micro level, i.e. the level of the individual. The individual life course can be divided into five distinct stages (before/at birth, childhood, young adulthood, adulthood, and old age). These stages are tied together by the principle of life-course effects (Komp, Johansson 2016; Ezdi 2017). The principle 
Figure 1: (Older) missing women in a life course framework

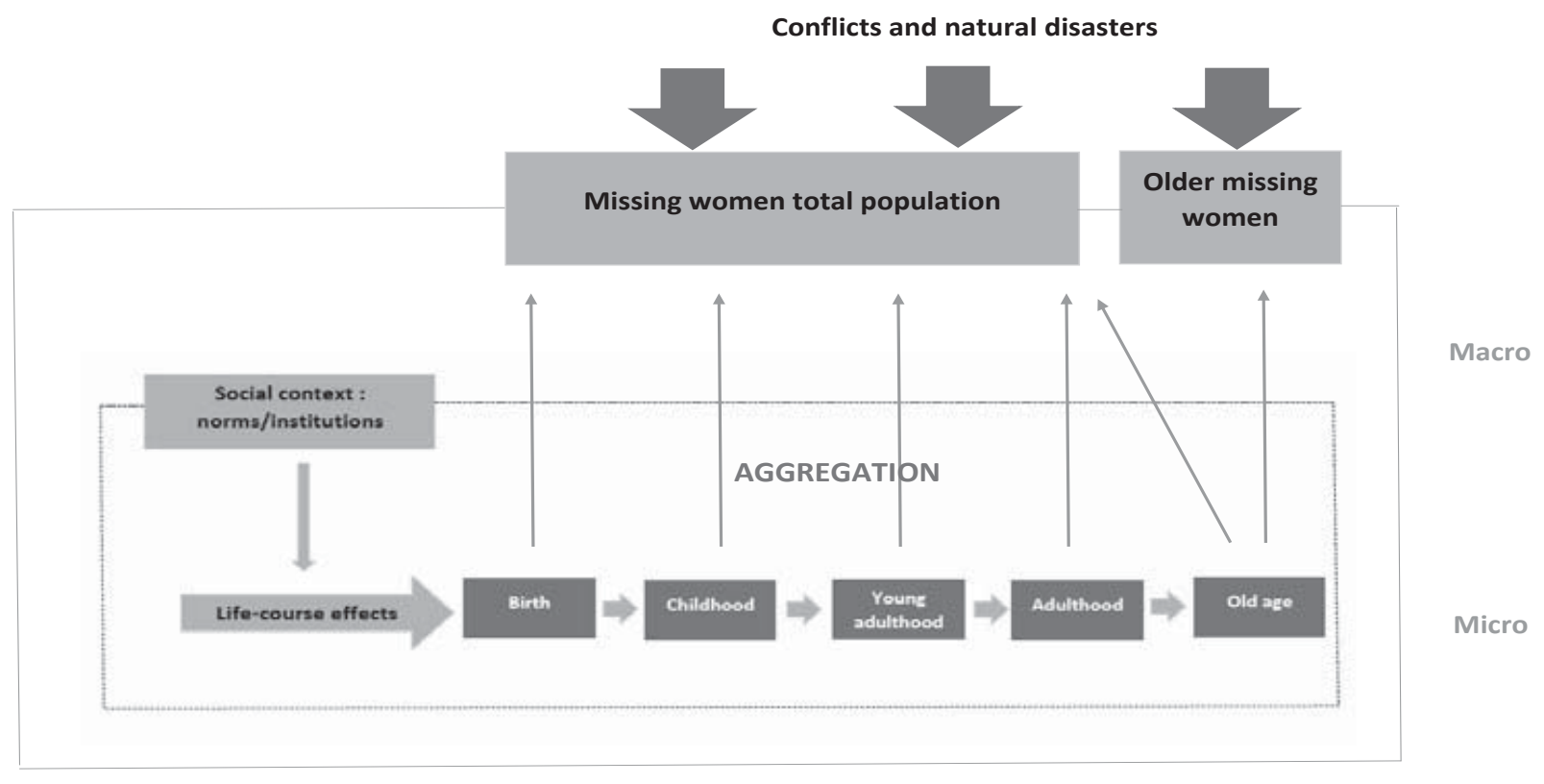

Source: Author's systematisation.

of life-course effect implies that what happens to individuals at an earlier point in life affects them at a later point in life (Komp, Johansson 2016). At the macro level, the individual life course is embedded in and governed by the social context (Elder Jr. 1994). The social context entails geographical and temporal elements, the effect of which are such that individuals and birth cohorts born at different times and places in different life stages and locations may be exposed to different varieties of disadvantages (Ryder 1965; Mayer 2004). The social context at the macro level differentiates the life courses of men and women by conceptualising factors and intermediary forces in the individual life courses of women. Factors are causal determinants of female mortality that either lead to missing women at the given life stage or create a female survival disadvantage at a subsequent life stage that precipitates premature mortality. Factors are assumed to be the result of predominantly social and behavioural differences in the treatment of men and women in society. Intermediary forces are elements that influence the effect of factors across the life course (e.g. education, income, social change) and thereby serve to exacerbate or depress the effect of the factors on the (older) missing women phenomenon. Figure 2 provides an overview of potential factors at each life stage and their possible interaction with intermediary forces, with a consequent impact on the (older) missing women phenomenon. ${ }^{1}$

1 The factors and intermediary forces delineated in Figure 2 have universal applicability, with the effects of factors and forces being stronger in some countries than others. 
As Figure 1 shows 1, the cumulative impact of factors and intermediary forces has the potential to lead to the premature mortality of the female birth cohort at each life stage so that by the time this birth cohort reaches the old age a significant fraction of the female cohort has been eroded, thereby creating a female deficit in the older population (Dannefer 2003; Ferraro, Shippee 2009). This deficit may be aggregated at each life stage by birth cohort to present the missing women phenomenon at that life stage (Coleman 1986). The older life stage marks the culmination of the female deficit for a given birth cohort (Coleman 1986). The summation of the missing women phenomenon across all life stages would then present the missing women phenomenon in the total population. Since the individual life course is a function of the society/country in which an individual belongs (i.e. social context) and is not indelible across time or geography (Mayer 2004), the factors and intermediary forces that affect individuals and, in their aggregate, the birth cohort at each life stage may vary across countries. As a result, the cumulative disadvantage that accrues to each birth cohort at each life stage, the resulting cumulative disadvantage in old age, and the consequent impact on female deficit in old age may also vary across countries (O'Rand 1996).

Independent of this endogenous mechanism, exogenous shocks in the form of conflicts and natural disasters (Figure 1) may create or exacerbate the missing women phenomenon at each life stage or in the total population. Cross-national studies provide evidence that in the case of civil conflicts, women and children are the most common long-term victims (morbidity and mortality) and in all types of conflicts long-term female mortality is at least as high as male mortality (Ghobarah Huth, Russett 2003; Li, Wen 2005). Empirical evidence also suggests that civil wars decrease the gender gap in life expectancy (Plümper, Neumayer 2006). Similarly, with the exception of famines, natural disasters reduce the gender gap in life expectancy (Neumayer, Plümper 2007). Consequently, conflicts and natural disasters are seen as discrete historical events that, by creating a system upheaval, may channel lives in a new direction by possibly altering patterns of continuity and creating change for specific groups of the population and thereby affecting existing configurations of social inequalities (Neugartan, Datan 1973; Mayer, Goedicke, Diewald 2006).

The theoretical foundation of the (older) missing women phenomenon makes two things evident. First, the (older) missing women phenomenon is the result of two groups of potential effects: factors across the life course and intermediary forces and/ or cohort effects in the form of conflicts and natural disasters. Second, the reasons for the (older) missing women phenomenon in different countries vary, as factors, intermediary forces, conflicts, and natural disasters are country specific. Therefore, the female deficit in old age displayed by the countries in Table 2, for example, may not just have distinct causational mechanisms but may also have accumulated across different stages of the life course. 


\section{Data and method}

\section{Data}

Data from UNDESA 2017 for the year 2015 are used for two types of analyses: first, to estimate the existence and magnitude of the older missing women phenomenon in the total, the 60+, the 75+ populations across countries in South Asia, with the inclusion and exclusion of immigrants. Second, to analyse the sex ratio (male/female) trajectory (by five-year age groups) of countries across South Asia that exhibit an (older) missing women phenomenon from the first exercise. These analyses are intended to complement each other, with the objective being not only to identify the existence of the deficit but also to confirm their life-course or cohort-effect interpretation and the likelihood of their persistence in future generations of the older populations in the affected countries.

The UNDESA follows a four-step procedure to construct its yearly population estimates. First, it collects data from census surveys, vital and population registers, and other national surveys. Second, it corrects the accuracy of the statistics collected by using post-enumeration surveys and demographic adjustment techniques. Third, it uses a balancing equation to check whether the estimates are consistent with each other and with the statistics corrected in the second step. Finally, since the UNDESA is producing estimates for countries all over the world, it crosschecks the consistency and balances the population estimates at the regional and world levels (UNDESAb 2015).

The population estimates and projections of the United Nations are based on the de facto population in a given country (UNDESAb 2015). According to the OECD (2006), the de facto population can be defined as 'a concept under which individuals (or vital events) are recorded (or are attributed) to the geographical area where they are present (or occurred) at a specified time'. Therefore, estimates of net migration (immigrants emigrants) need to be subtracted from the population estimates to obtain an accurate demographic profile of the nationals of any given country. Such an exercise would require flow data by gender and age on South Asian countries. Although flow estimates for the population as a whole may be available for some South Asian countries, ${ }^{2}$ they are not disaggregated by gender and age and therefore cannot be used to calculate sex ratios by age. The best alternative, especially for South Asian countries, is the gender and age distribution of the international migrant stock that is provided by the UNDESA (Fargues 2006; Cainkar 2013). The United Nations defines the international migrant

\footnotetext{
2 Abel and Sander (2014) convert migrant stock data provided by the United Nations Population Division into flow data, thereby providing flow estimates for 196 countries in the world. The United Nations Population Division provides flow estimates for 43 countries worldwide, most of which are in Europe and North America. However, the data provided by Abel and Sander (2014) are not disaggregated by age or gender and therefore cannot be used for the purpose of this paper.
} 


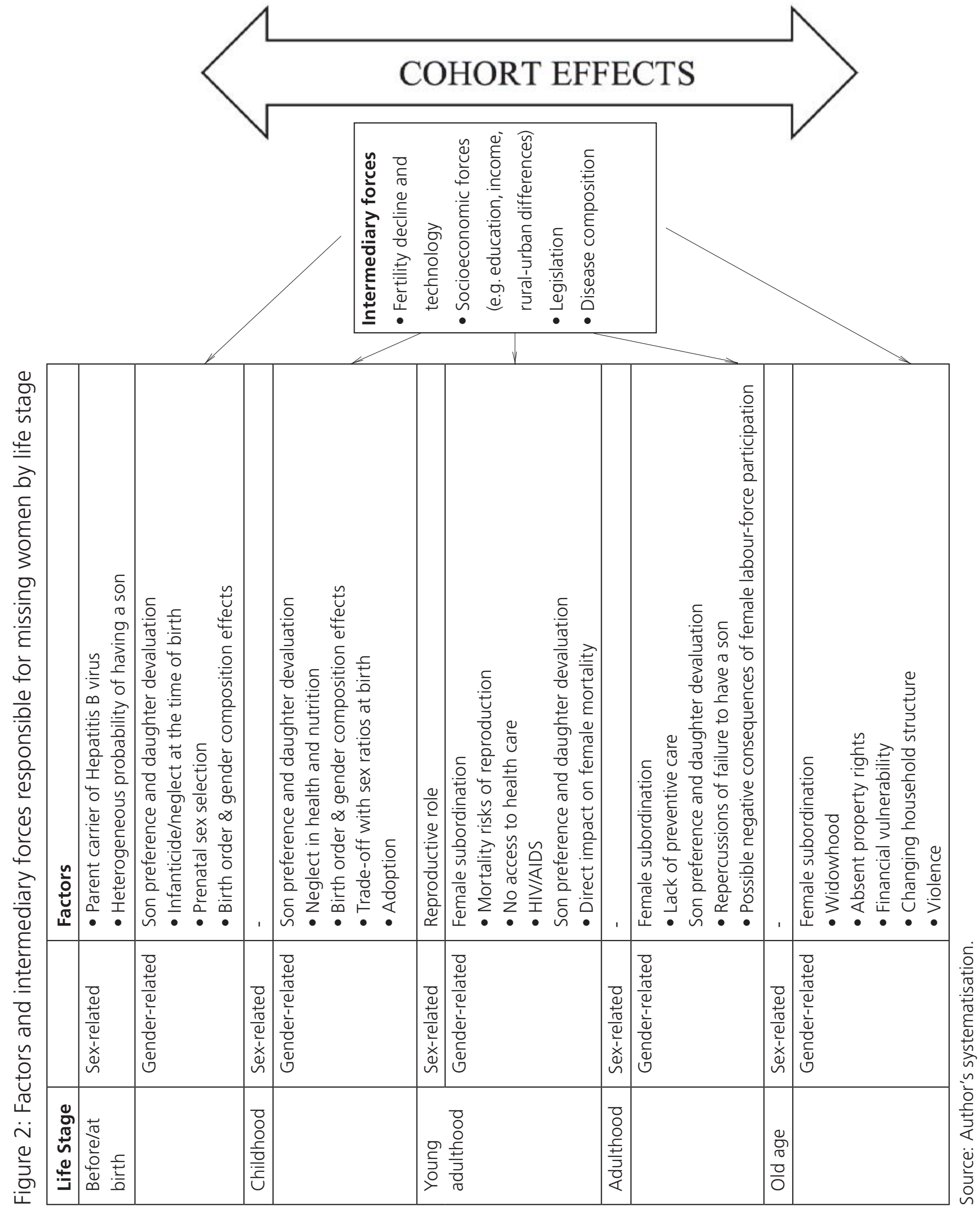


stock as 'the number of people born in a country other than that in which they live, including refugees' (UNESCO 2010). Therefore, UNDESA data on migrant stock are used to analyse sex ratios, with the exclusion of immigrants.

\section{Methodology}

The primary methodological consideration in calculating the number of missing women in any age group is the identification of the hypothetical number of women that should be alive in the given age group in the absence of missing women. This requires the identification of an ideal sex ratio (male/female) that would prevail in the absence of missing women. This was one of the earliest problems to emerge in the missing women literature by the pioneer authors in this area (i.e. Sen 1990; Coale 1991; Klasen 1994), in which there were debates about the ideal reference standard that should be used to calculate the number of missing women in the population. This debate is also apparent in relation to the time of birth, where one would expect that, in the absence of intervention, sex ratios would approach the same biologically normal levels across different countries. However, not only does the biological standard at birth differ across populations (e.g. populations of Sub-Saharan Africa or African American descent have lower sex ratios at birth; Garenne 2009), but also the sex ratio at birth is connected with the life expectancy of the population such that populations with longer life expectancies (e.g. industrialised Western countries) may be expected to have higher sex ratios at birth (Klasen 1994). While literature attempts to correct for these discrepancies the problem remains that if the ideal standard of comparison at the earliest life stage varies, the benchmark for subsequent life stages would be imprecise. This may be especially evident in the young adult and adulthood stages, where women's reproductive role predisposes them to certain risks that men are not exposed to and this makes it difficult to disentangle excess female mortality through this channel from normal levels of mortality (Anderson, Ray 2010). For example, it seems unlikely that in any country maternal mortality (or the cumulative disadvantages thereof) could fall to zero and some reference mortality rate would be needed (Anderson, Ray 2010).

To overcome such pitfalls, the world sex ratio (male/female) has been used as the standard of comparison for South Asian countries: the sex ratios in the total, the $60+$, and the $75+$ populations and in each five-year age category for each country must be less than or equal to the respective world sex ratio. This ensures a conservative measure as not only are South Asian countries with their relatively large populations included in the world average but also other countries like China and Middle Eastern countries of Asia (proven to have large female deficits in their total and older populations; Ezdi, Künemund 2019), thereby masculinising the world sex ratio and preventing an overestimation of the missing women phenomenon. Hence, 
using world sex ratios would lead to an optimal solution, with higher sex ratios in some countries being offset by lower sex ratios in other countries, and would provide an average for comparison in the respective age categories.

For the first analysis, the sex ratios (male/female) of each South Asian country are subtracted from the world sex ratios for the specific age category and the total population (the latter for comparative purposes, discussed in detail in the results section). A negative number indicates an older missing women phenomenon in the given age category and country (as the ratio of men/women of that country is higher than the ratio of men/women for the world) and a zero or positive number indicates no older missing women phenomenon in the given age group and country, compared to the world average. This analysis is conducted including and excluding the immigrant stock for each country, as it will become evident in the subsequent discussion, age- and gender-specific immigration patterns in some countries may distort the findings.

In the second analysis, the sex ratio trajectory by five-year age groups for countries identified as presenting the older missing women phenomenon in the first analysis is examined with respect to the world sex ratio (male/female) trajectory by five-year age groups, and the differences with the inclusion and exclusion of immigrant stock are evaluated. As mentioned earlier, the purpose of the second analysis is to assess the age distribution of missing women to check the age at which the female deficit is concentrated and confirm whether or not the deficit in the older population is large enough to create a female deficit in the total population.

\section{Results}

\section{Sex ratios (male/female) by broad age categories}

Figure 3 presents the results for the sex ratios (male/female) for the total, the 60+, and the $75+$ populations in South Asian countries as deviations from the world average. Columns below the mean indicate a female deficit in the respective age category in a given country. 
Figure 3: Sex ratios for South Asian countries in 2015, including immigrants

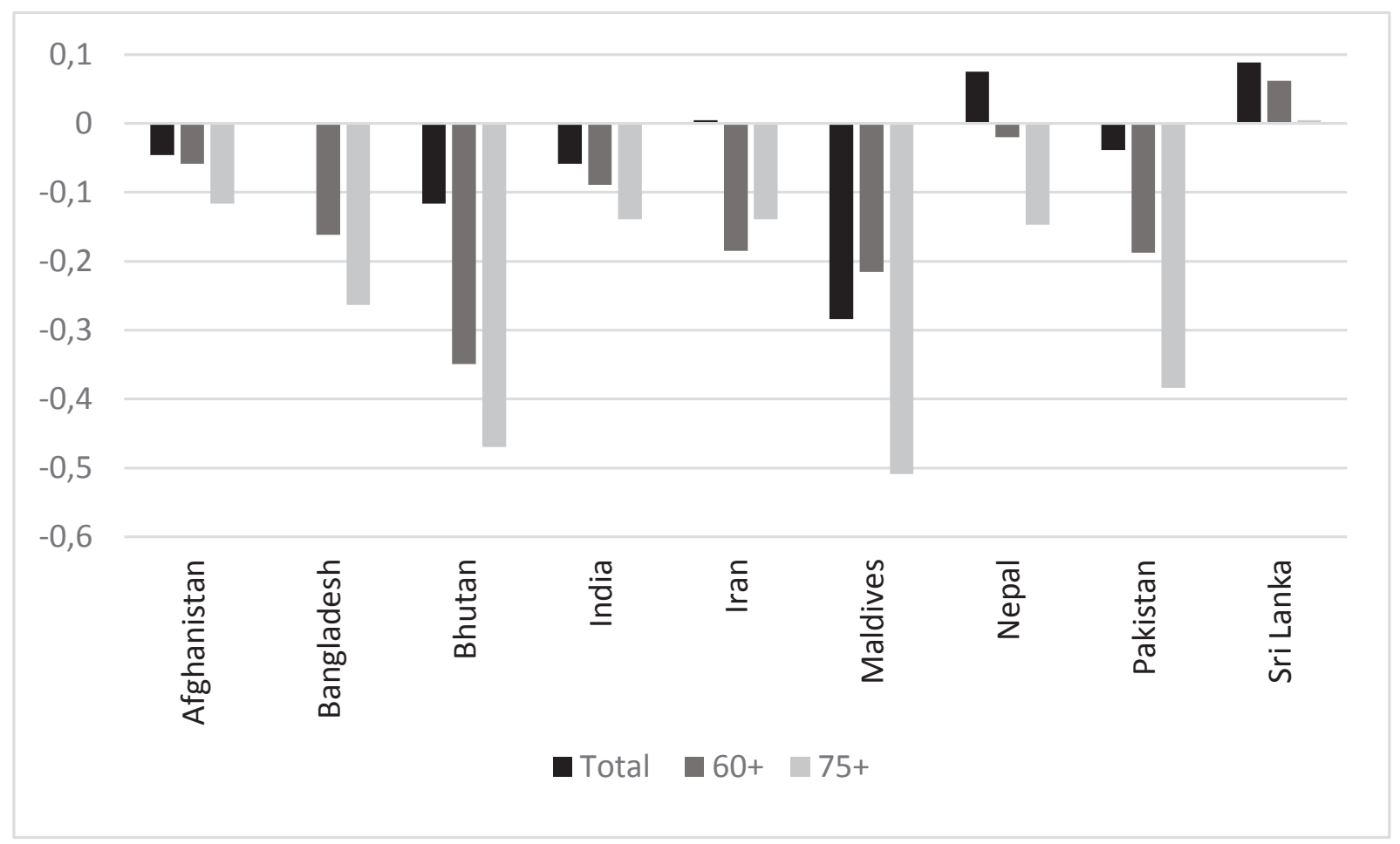

Source: United Nations Department of Economics and Social Affairs (2017), author's calculations.

Figure 3 shows that, with the exception of Sri Lanka, all countries in South Asia exhibit an older missing women phenomenon due to a female deficit in both their $60+$ and $75+$ age categories. The most dramatic deviations from the world average seem to exist in Bhutan for the 60+ population and in Maldives, Bhutan, and Pakistan for the $75+$ population. At first glance Sri Lanka appears to be an outlier in the opposite direction for the $60+$ population, perhaps indicating higher male mortality in the past. However, this may also reflect the standard of comparison, i.e. the world average, which includes all countries. If the standard of comparison were the industrialised countries of Western Europe perhaps even Sri Lanka would display a female deficit in the $60+$ population.

A comparison of the female deficit for the selected countries by age groups with the result for total population may provide hints at a cohort effect, i.e. if the female deficit appears only in older age categories and not in the total population then the population formulating the respective older $(60+)$ age category today may have suffered from conflicts or natural disasters in younger age groups that led to the creation or precipitation of this female deficit. This appears to be the case for Iran and Nepal as deficits in the older population $(60+$ and $75+)$ are accompanied by a surplus in the total population (albeit small in the case of Iran). This finding is reinforced by the observation that the difference between the female surplus in the total population 
and female deficits in the older population, in both countries, is substantial enough to consider that an exogenous force may have at least precipitated the predominance of the missing women phenomenon in the older category.

For the six remaining countries that display the older missing women phenomenon, i.e. Afghanistan, Bangladesh, Bhutan, India, Pakistan, and Maldives, the female deficit in old age is accompanied by a female deficit in the total population. For the first five countries, the female deficit in the older population $(60+, 75+)$ exceeds the female deficit in the total population. This could indicate an increased vulnerability among older women either due to an exacerbation of gender inequalities in old age or a lifetime accumulation of female disadvantages. It could also indicate a trend over time. Maldives is the only country where the female deficit in the total population exceeds the female deficit in the $60+$ population. However, as the population ages, i.e. from $60+$ to $75+$, the female deficit in the older population exceeds that of the total population. This may be indicative of male-dominated immigration in Maldives (UNESCAPS 2010). Sex ratios may become less masculinised in the 60+ population as labour immigrants leave the country at the end of their working years and more masculinised in the $75+$ population as the gender inequalities faced by the local population in old age surface.

To control for the potential distortion caused by immigration (even if it is expected to significantly alter sex ratios in Maldives only), Figure 4 recalculates the preceding estimates by excluding immigrants in South Asian countries. The revised estimates show essentially the same patterns as with the inclusion of immigrants for Afghanistan, Bhutan, India, Iran, Nepal, Pakistan, and Sri Lanka. However, the older missing women phenomenon in Bangladesh now appears to be a cohort effect. This change indicates a slight masculinisation of immigration in Bangladesh, as the female deficit in the total population, when immigrants are included, is imperceptible (Figure 3) and the female surplus, when immigrants are excluded, is relatively small (Figure 4). The exclusion of immigrants also alters the results for Maldives. Not only is there a substantial reduction in the female deficit in the total population but also the older missing women phenomenon in the country is concentrated in the 75+ population only, and it continues to follow a life-course explanation. This may point to the presence of a female surplus as a cohort effect in the younger-old age bracket in the country (aged 60- 75 years). Without historical cohort-specific data, the existence of the age-specific discrimination of older women cannot be completely ruled out (such as would result from - just to provide a drastic example - the ritual burning of widows). Therefore, the hypothesis of female discrimination occurring in the past and accumulating into older age groups today is much more plausible. 
Figure 4: Sex ratios for South Asian countries, excluding immigrants

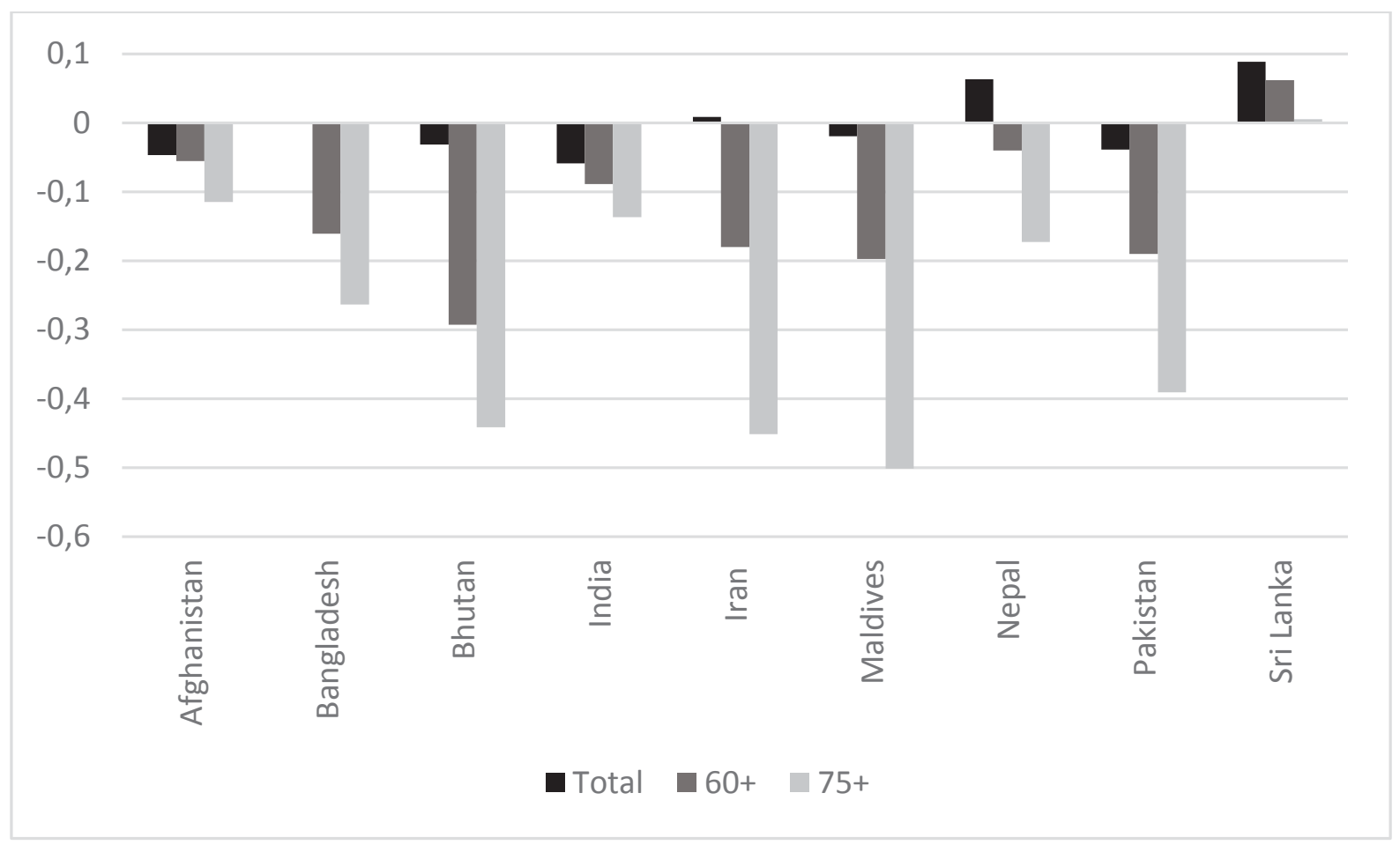

Source: United Nations Department of Economics and Social Affairs (2017), author's calculations.

\section{Sex ratio trajectory by five-year age groups}

To verify these previous findings, Figures 5 to 12 trace the sex ratio (male/female) trajectories by five-year age groups for countries in South Asia that exhibit a female deficit. The figures show the trajectory both with the inclusion and with the exclusion of immigrants and present the world sex ratio trajectory for comparative purposes.

Figures $5,6,7$, and 8 show that the sex ratio trajectories with the inclusion and exclusion of immigrants for Afghanistan, India, Iran, and Pakistan are not only identical but also overlap. This shows that either there is no immigration in these countries or that immigration is not distorted in favour of either gender. The age distribution of a female deficit in India clearly reveals the persistence of a female deficit in each fiveyear age category, starting from birth and continuing into old age. This points to the persistence of a female survival disadvantage across the life course, thereby supporting the previous results. In Afghanistan and Pakistan, the female deficit appears after a specific age category (20+ in Afghanistan and $45+$ in Pakistan) and, on average, continuously worsens in each subsequent age category. This allows for both a lifecourse explanation and cohort-effect explanation for the female deficit, especially in Pakistan where this effect is more pronounced. On the one hand the $20+$ population in Afghanistan and the $45+$ population in Pakistan may have been exposed to specific 
events (conflicts and/or natural disasters) that have led to excess female mortality in these countries. On the other hand, the female survival disadvantage may be most pronounced at the aggregate level within these age categories and may continuously accumulate well into old age. A joint explanation is also likely. As discussed in the next section, conflicts and natural disasters have been shown to exacerbate existing gender inequalities and worsen the life expectancy and survival advantage/disadvantage of women especially in the long run (Plümper, Neumayer 2006; Neumayer, Plümper 2007). Given the different possibilities for the older missing women phenomenon, the results for Afghanistan and Pakistan are consistent with those previous findings. The sex ratio trajectory of Iran is highly erratic, displaying female deficits in some age categories and female surpluses in other age categories. However, the magnitude of the deficit in the older categories vis-à-vis the surplus and deficits in other younger age categories would support a cohort-effect interpretation of the country, thereby supporting the previous results. At the same time, Figure 8 indicates that selected younger age categories (e.g. ages 40-54) in the country that display a female deficit in 2015 will create an older missing women phenomenon in the future as they enter the older $(60+)$ category.

Figure 5: Sex ratio trajectory (male/female), Afghanistan (2015)

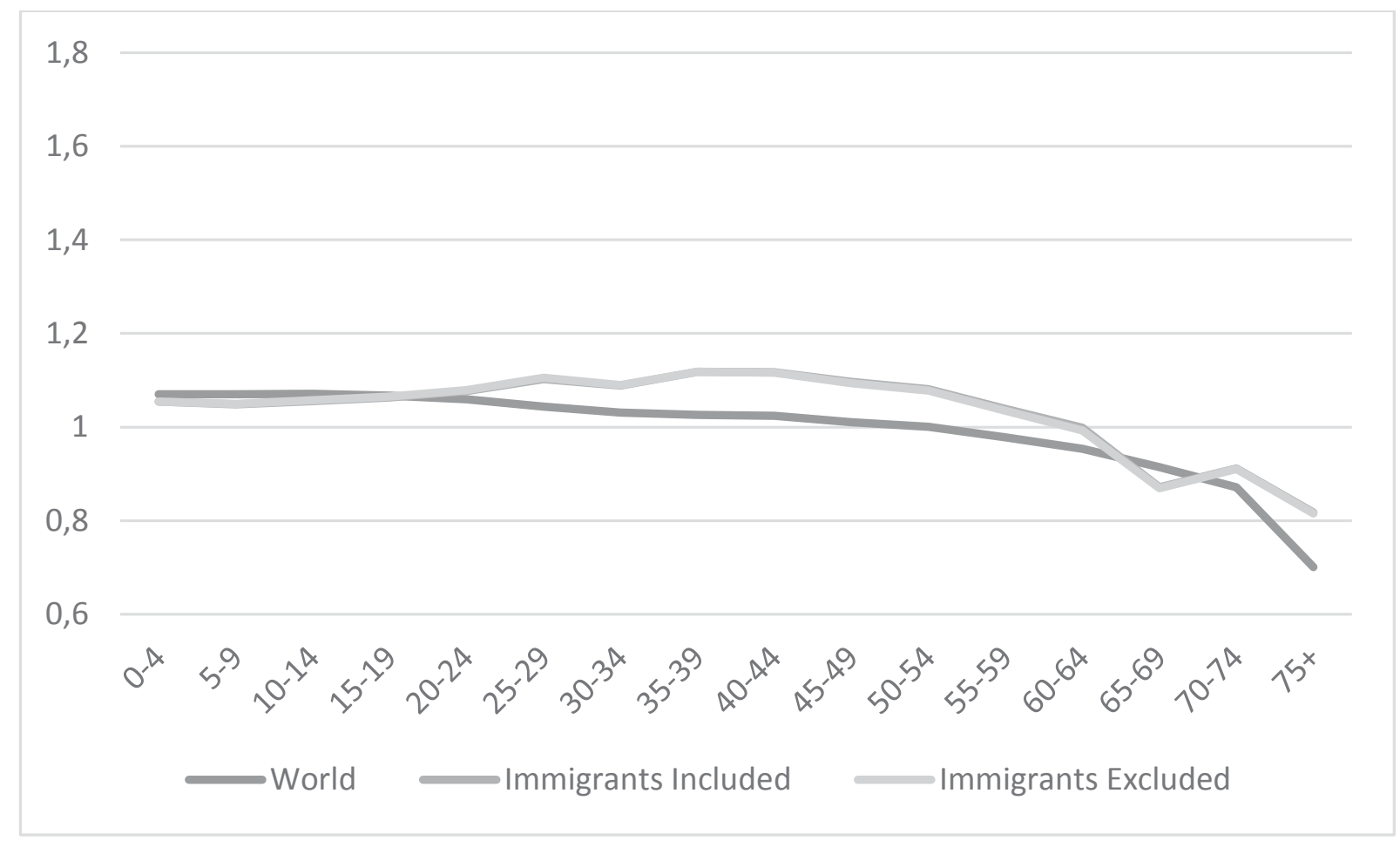

Source: United Nations Department of Economics and Social Affairs (2017), author's calculations. 


\section{NV STATI / ARTICLES}

Figure 6: Sex ratio trajectory (male/female), India (2015)

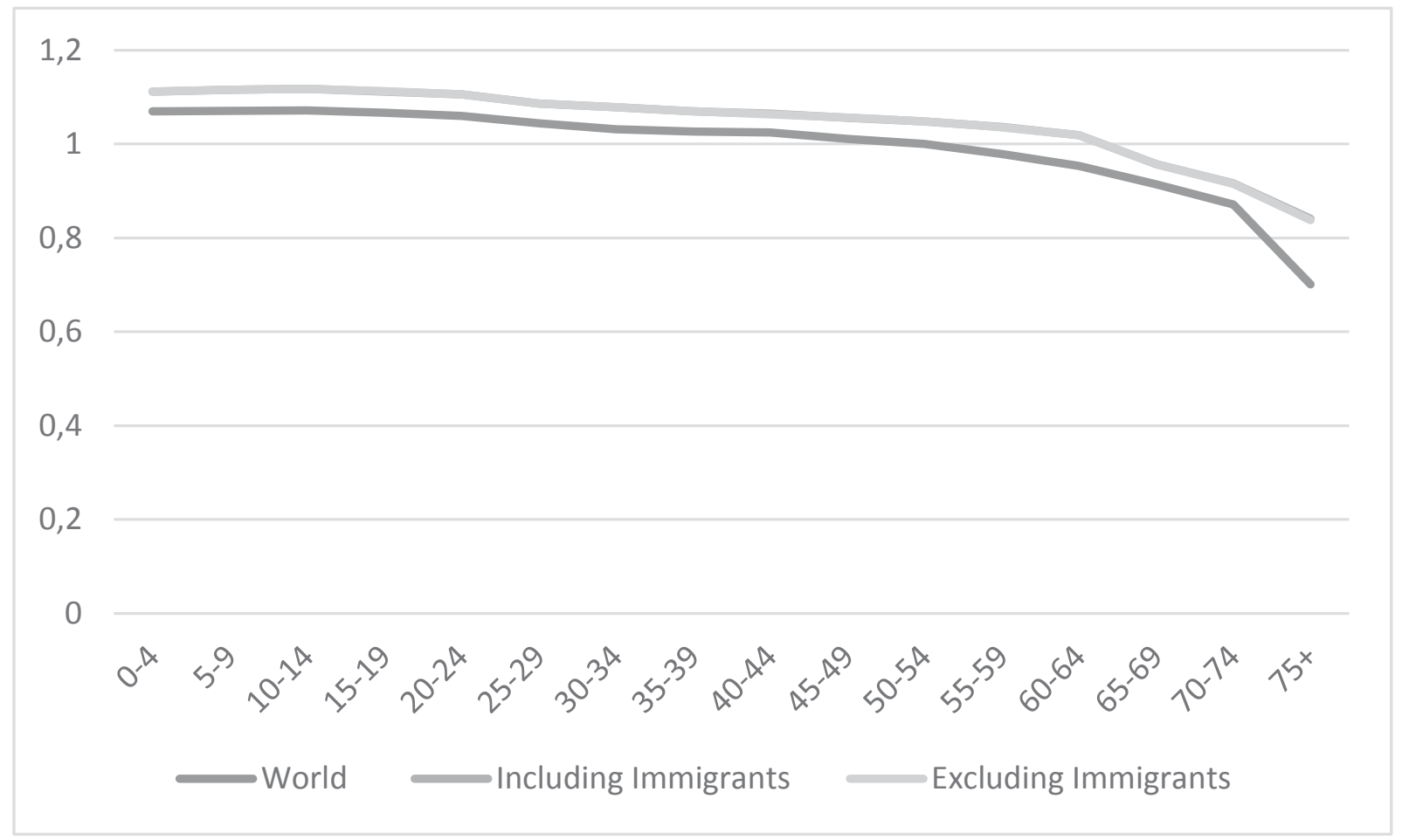

Source: United Nations Department of Economics and Social Affairs (2017), author's calculations.

Figure 7: Sex ratio trajectory (male/female), Iran (2015)

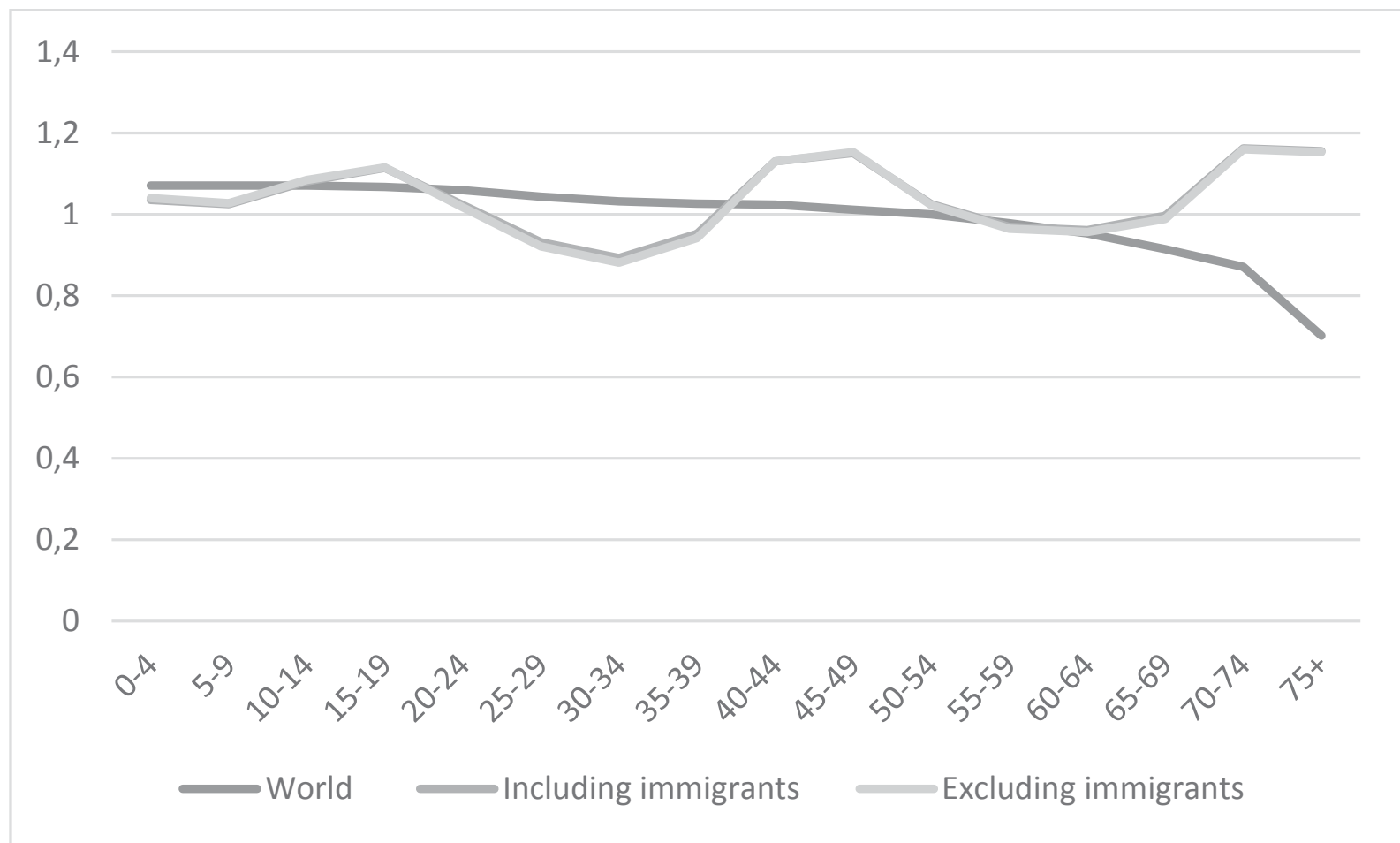

Source: United Nations Department of Economics and Social Affairs (2017), author's calculations. 
Figure 8: Sex ratio trajectory (male/female), Pakistan (2015)

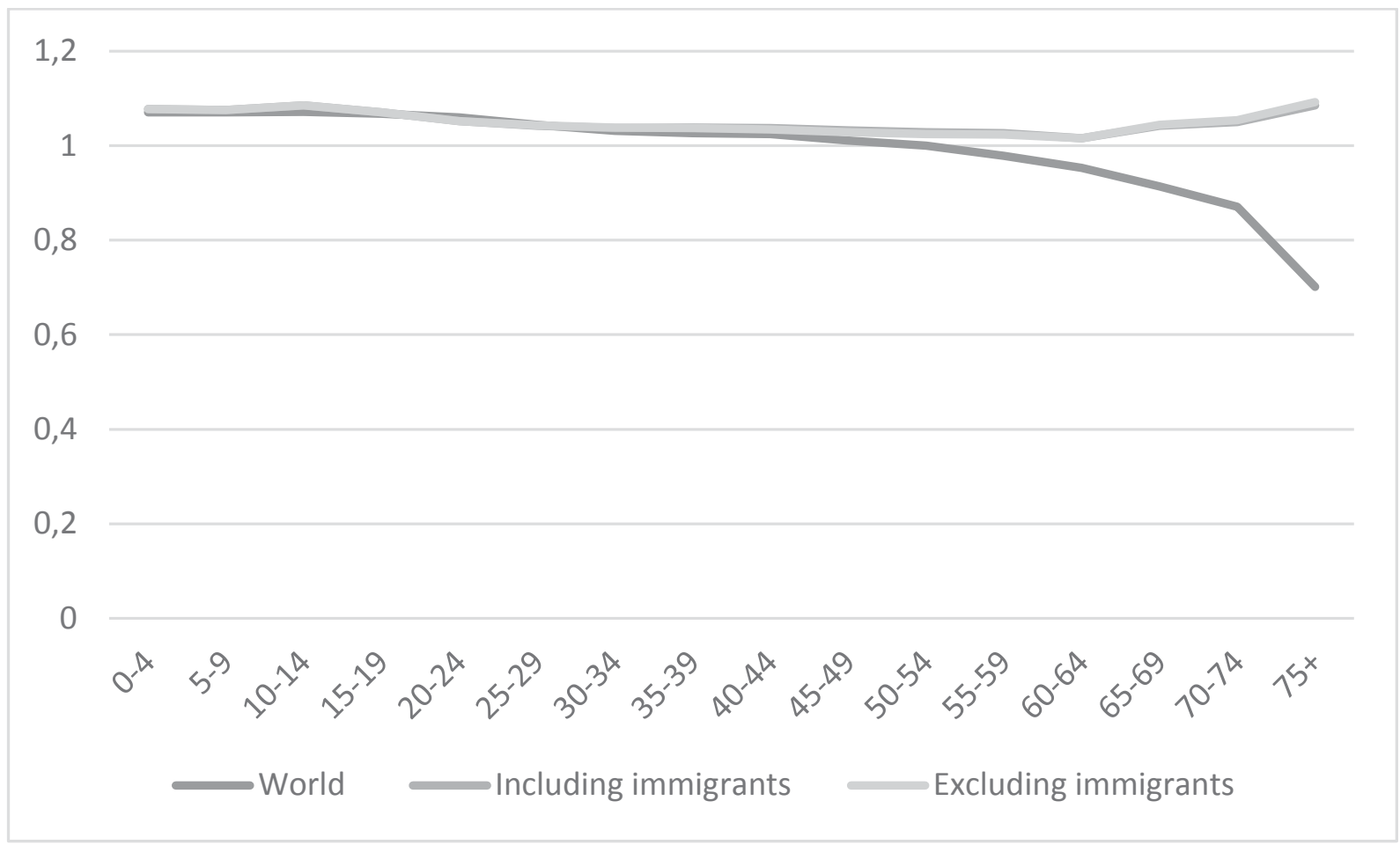

Source: United Nations Department of Economics and Social Affairs (2017), author's calculations.

Figures 9, 10, 11, and 12 show that the sex ratio trajectories of Bangladesh, Bhutan, Maldives, and Nepal with the inclusion and the exclusion of immigrants are identical but do not overlap. In both Bangladesh and Bhutan, the exclusion of immigrants leads to an overall reduction in the female deficit. In both countries the bulk of the reduction is concentrated in the working age categories. Consequently, the female deficit is concentrated in the $45+$ population for Bangladesh and the $30+$ population for Bhutan. The situation in these two countries is therefore similar to Afghanistan and Pakistan in allowing for a life-course explanation, cohort-effect explanation, or joint explanation for the female deficit, and it is therefore consistent with previous findings. In Maldives, the exclusion of immigrants also leads to an overall reduction in the female deficit and converts the female deficit in the 40-74 age category into a female surplus. Consequently, the female deficit is concentrated in the 15-39 and $75+$ age categories. The results from Figure 4 show that the female deficit in these two age categories is large enough to offset the surplus in the remaining age categories. Therefore, in contrast to the previous results and the sex ratio trajectory that includes immigrants, the sex ratio trajectory that excludes immigrants yields a cohort-effect interpretation for the older missing women phenomenon in Maldives. Figure 11 further shows that, like in Iran, an older missing women phenomenon may be expected to re-appear in the future as the population aged 15-39 in 2015 enters 


\section{NV STATI / ARTICLES}

the older category. In Nepal, Figure 12 shows a slightly feminised immigration trend. In Nepal, with the inclusion of immigrants the female deficit only appears in the older age category, thereby supporting the previous results. With the exclusion of immigrants, alongside the female deficit in the older population there is a negligible female deficit in the 50-59 age category. Given the magnitude of the deficits and surplus, the cohort-effect interpretation, in accordance with the previous results, continues to hold, with the expectation that, like in Iran and Maldives, the country will continue to exhibit an older missing women phenomenon in the near future due to the female deficit observed in the population aged 50-59.

Figure 9: Sex ratio trajectory (male/female), Bangladesh (2015)

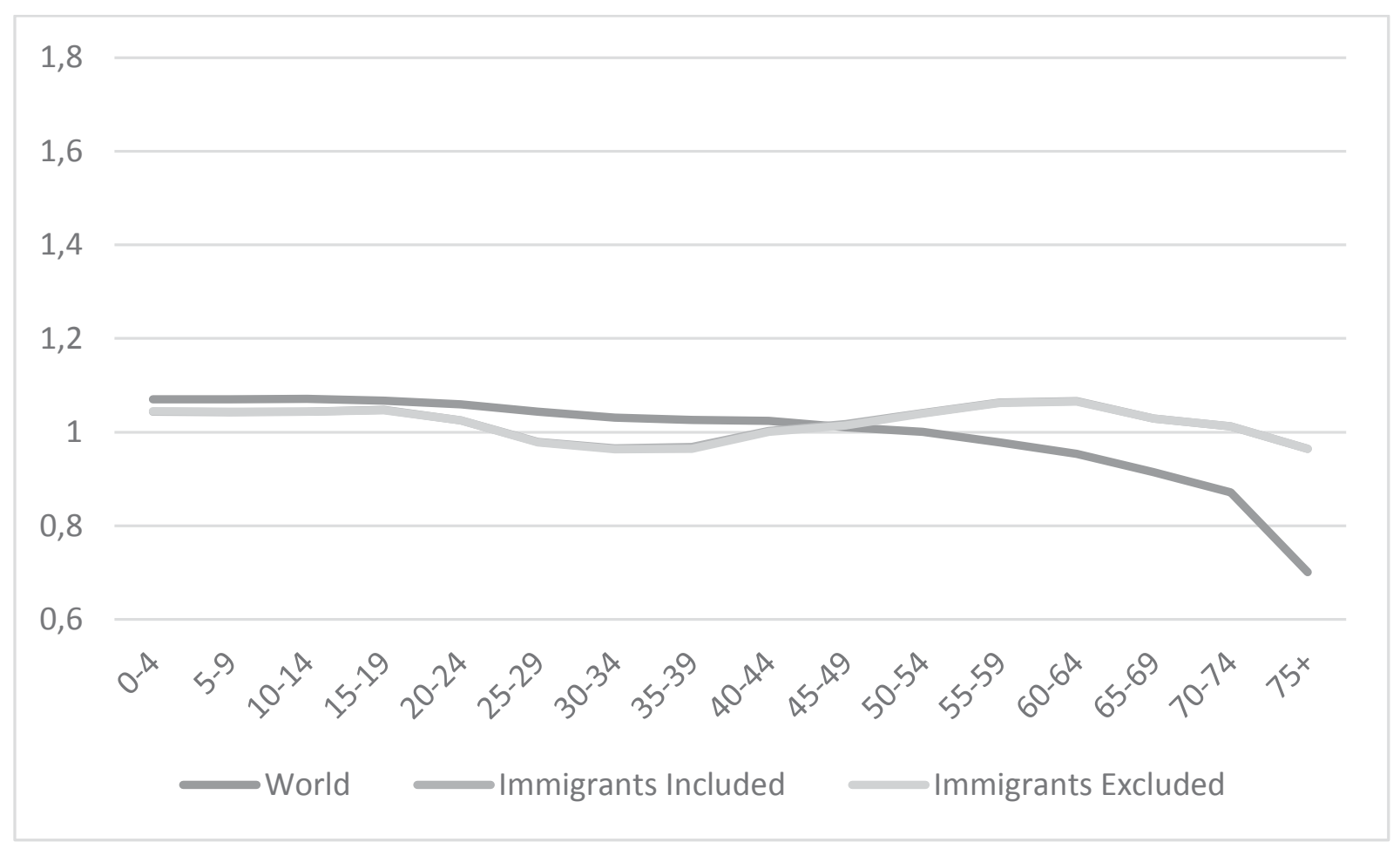

Source: United Nations Department of Economics and Social Affairs (2017), author's calculations. 
Figure 10: Sex ratio trajectory (male/female), Bhutan (2015)

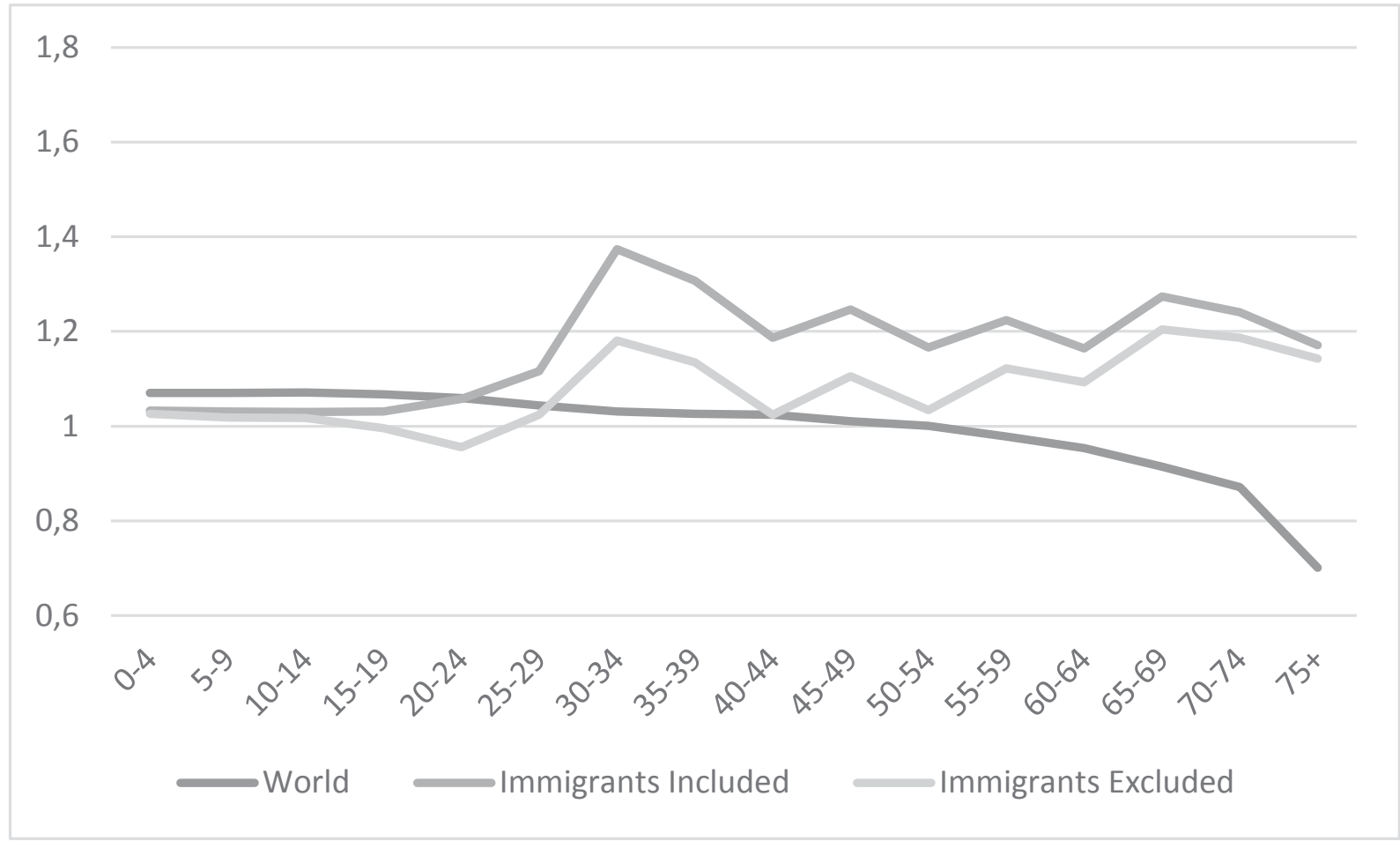

Source: United Nations Department of Economics and Social Affairs (2017), author's calculations.

Figure 11: Sex ratio trajectory (male/female), Maldives (2015)

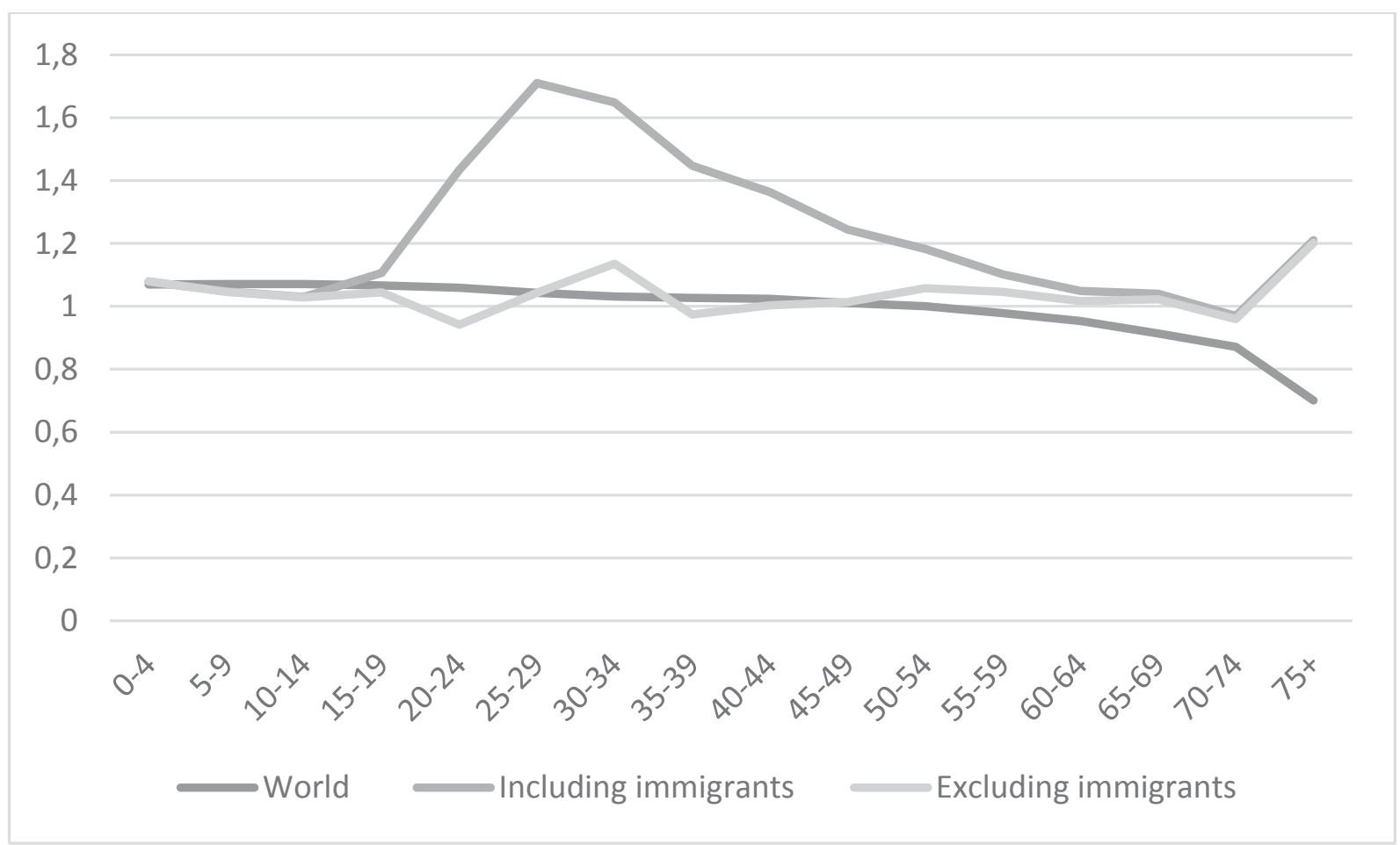

Source: United Nations Department of Economics and Social Affairs (2017), author's calculations. 
Figure 12: Sex ratio trajectory (male/female), Nepal (2015)

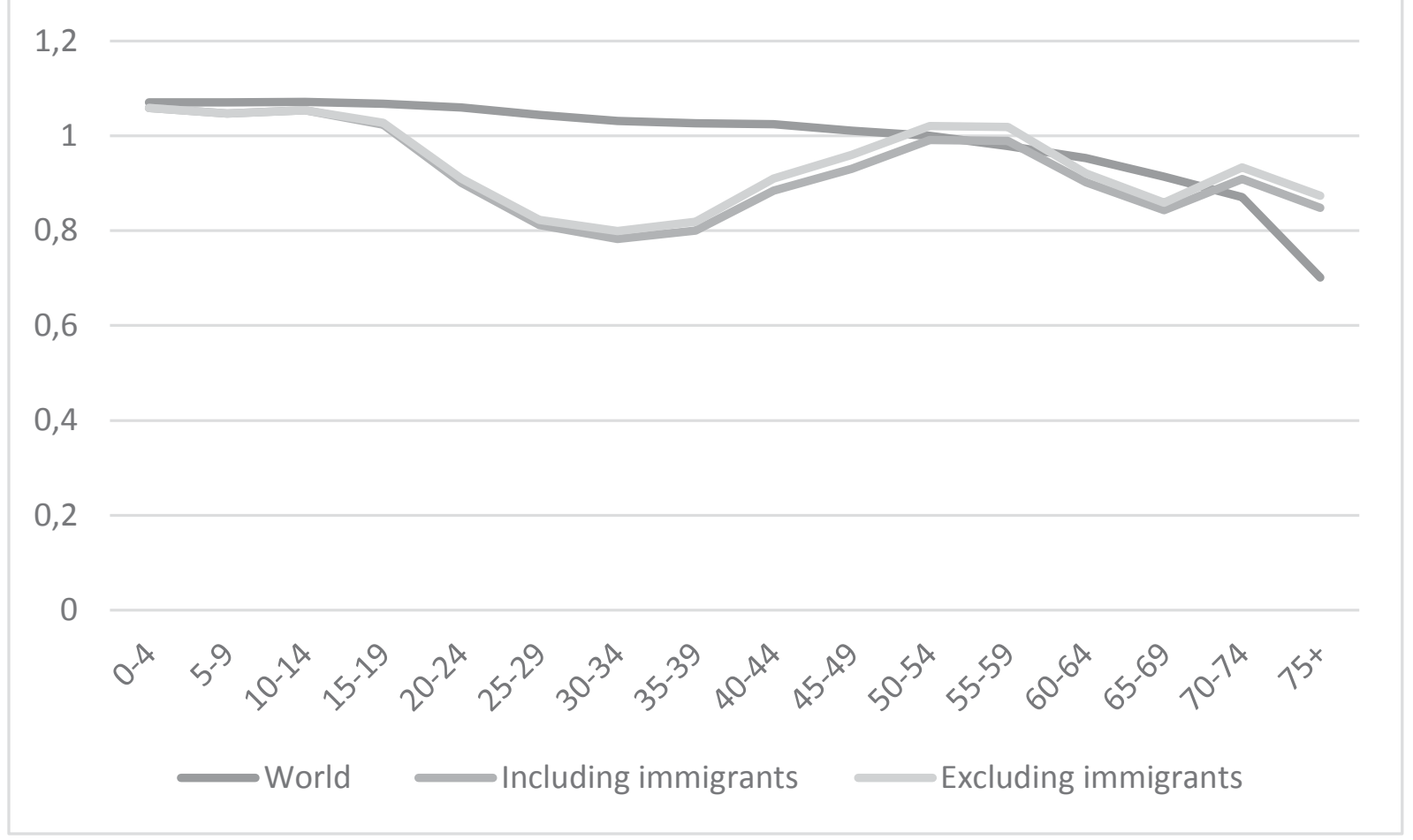

Source: United Nations Department of Economics and Social Affairs (2017), author's calculations.

\section{Discussion}

The results indicate the presence of an older missing women phenomenon, both with the inclusion and with the exclusion of immigrants, in all countries of South Asia except Sri Lanka. In India, the results allow for a clear life-course explanation for the phenomenon as the deficit is persistent across all age categories. However, as the deficit does not worsen with age, a hypothesis of cumulative survival disadvantage cannot be confirmed from these results. In Nepal and Iran, the phenomenon can be explained as a cohort effect, as it is not persistent across all ages and may fade as younger cohorts enter old age. Nevertheless, there is a potential for the re-emergence of the phenomenon in these countries as younger cohorts who display a female deficit enter the older category. In Afghanistan, Bangladesh, Bhutan, and Pakistan, the phenomenon may be explained as a combination of the life course and cohort effects, in that conflicts and/or natural disasters may have exacerbated existing gender inequalities and precipitated the female survival disadvantage. The cumulative nature of this deficit as the population ages lends further credence to this argument. Maldives is the only country where immigration alters the main results.

The results depicting the effect of immigration on the female deficit in affected South Asian countries are compatible with the literature on immigration trends in the region. The exclusion of immigrants leads to the feminisation of the sex ratio trajectory in 
Maldives, Bhutan, and Bangladesh, with the strongest effect observed in Maldives and the weakest effect in Bangladesh. Both Maldives and Bhutan are labour-receiving countries, where the sex ratios of immigrant workers are highly skewed in favour of males: $92 \%$ of the registered immigrant workers in Maldives and $99 \%$ of the immigrant workers in Bhutan are male (UNESCAP 2010). Although Bangladesh is primarily a labour-exporting country, Rohingya refugees from Myanmar and a limited number of foreign workers form its relatively small immigrant population (UNESCAP 2010; Wickramasekara 2011). The feminisation of the sex ratio trajectory that occurs on the exclusion of immigrants may be due to the masculinisation of foreign workers in the country. In Nepal the exclusion of immigrants leads to the feminisation of sex ratios in the country. This is because amongst all South Asian countries (including Sri Lanka), Nepal has the most feminised immigrant population, with women accounting for more than half of the total immigrant stock in the country (UN 2017; Timothy, Sasikumar 2012).

In Afghanistan, Iran, Pakistan, and India the sex ratio trajectories with the inclusion and exclusion of immigrants are identical. Migrant inflows in the latter three countries primarily consist of refugees and return refugees (UNESCAPS 2010). Return refugees to Afghanistan, Afghan refugees in Pakistan, and Afghan and Iraqi refugees in Iran predominate among the immigrant populations in these three countries, respectively (Majidi 2017; UN 2017). In addition, a relatively small fraction of Pakistani and Nepalese workers in Afghanistan and a fraction of Chinese workers in Pakistan comprise the immigrant population in the respective countries (UNESCAPS 2010). A consequent 1:1 ratio of men to women amongst these immigrants may explain the identical sex ratio trajectories upon the inclusion and exclusion of immigrants in these countries. ${ }^{3}$ India has the third most feminised immigrant stock in South Asia (followed by Nepal and Sri Lanka; Timothy, Sasikumar 2012). From 1990 to 2010 female immigrants formed approximately $48-49 \%$ of the immigrant stock, indicating a roughly equal proportion of men and women in the immigrant population, leading to identical sex ratio trajectories upon the inclusion and exclusion of immigrants (Timothy, Sasikumar 2012).

It may be argued that given the emigration and migration profiles of the South Asian countries displaying the female deficit, the failure to account for emigration merely leads to an underestimation of the (older) missing women phenomenon. Although South Asian countries are classified as net emigration countries because of the high emigration versus immigration rates, with the exception of Sri Lanka, the

\footnotetext{
${ }^{3}$ Note: A sex ratio (male/female) of 1 does not mean that the (older) missing women phenomenon is absent because, as the population ages, the preponderance of women in the population is expected to increase and the sex ratios (male/female) decrease.
} 


\section{STATI / ARTICLES}

share of female emigrants from countries in the region remains disproportionately low (Wickramasekara 2011; Timothy, Sasikumar 2012; UN 2017). Restrictive emigration policies have limited female outflows in the past in Bangladesh, India, Pakistan, and Nepal and, at a minimum, men continue to make up more than $50 \%$ of emigrants from these countries (ILO 2014; Timothy, Sasikumar 2012, Simkhada et al. 2018). From Afghanistan, Bhutan, and Maldives combined, women comprise $0.8 \%$ of the international migrant stock of South Asia, so men predominate in the emigration flows there (UNESCAPS 2010; UN 2017). A similar situation holds for Iran, where, leaving Afghan return refugees aside, OECD data reveals a predominance of male over female Iranian emigrants in highly skilled occupations (Dumont et al. 2007). These patterns of emigration make it clear that the results provide a conservative measure of the extent of the (older) missing women phenomenon in respective South Asian countries and that the problem is significantly more serious than depicted in this paper.

While the absence of emigration data may not limit this analysis, the lack of longitudinal data for the majority of affected countries makes it difficult to identify the exact causal mechanisms behind the (older) missing women phenomenon. In the case of India, a substantial body of literature provides evidence of factors throughout the life course as the main causative mechanism, examples of which include: sex-selective abortion at before/at the time of birth (Manchanda et al. 2011); gender discrimination in nutrition and health care during childhood (Das Gupta 1987); reproductive mortality in young adulthood (Sanneving et al. 2013); violence in adulthood (Anderson, Ray 2010); and poverty in old age (Dreze, Srinivasan 1997). The results for India in this paper support this body of literature. In addition, the availability of representative longitudinal data for the $45+$ population in the country may allow for a further elaboration of the causal mechanisms. For the remaining countries it is interesting to note that neither of the countries display a female deficit at the time of birth, a causal factor that is not only immediately evident in sex ratios and is non-cumulative in terms of survival disadvantage but has also predominated in the literature on the missing women phenomenon. With the exception of Maldives and Nepal, this may be explained by religion. In Afghanistan, Bangladesh, Iran, Maldives, and Pakistan, over $90 \%$ of the population is Muslim (PEW 2019). The literature on sex selection at birth in India and amongst immigrant communities in Western countries provides strong evidence of the absence of sex selection behaviour amongst Muslims (e.g. Borooah, lyer 2004; Almond, Edlund, Milligan 2013). Therefore, in Afghanistan, Bangladesh, and Pakistan factors after the stage of birth are more likely, whereas in Maldives and Iran the cohort-effect explanation (conflict/natural disasters) is the likely causative mechanism.

Substantial literature on Afghanistan, Bangladesh, and Pakistan points to the persistence of gender inequalities at all ages after birth across these countries (e.g. 
Zaman 1999; Bartlett et al. 2005; Qureshi 2012). These gender inequalities are similar to those identified for India after the stage of birth in the preceding paragraph. The previous results, however, indicate that the deficit does not emerge immediately after birth but rather in the $20+$ population in Afghanistan and in the $45+$ populations in Bangladesh and Pakistan. Given the evidence from the literature, this may be attributable to a worsening of discrimination in these countries, which may or may not have been triggered by conflicts or natural disasters. The likelihood of conflicts and natural disasters having operated as a cohort effect is entirely plausible given the history of these countries. From 1946 to 2017, the UCDP/PRIO armed conflicts database records 40 conflicts for Afghanistan, 13 conflicts for Pakistan, 11 conflicts for Iran, and 4 conflicts for Nepal, these being conflicts in which the total death toll had exceeded 1000 deaths $^{4}$ (Gleditsch et al. 2002; Petterson, Eck 2018)5. The Emergency Disasters Database records the following numbers of deaths by natural disasters for each country over the past 70 years: 16,025 in Afghanistan; 200,000 in Bangladesh; 304 in Bhutan; 131,353 in Iran; 325 in Maldives; 15,802 in Nepal and 97,988 in Pakistan (Guha-Sapir 2016). These figures indicate the occurrence of conflicts and natural disasters that have the potential to have a lingering and long-term detrimental impact on female mortality and could thereby either give rise to a female deficit or exacerbate the already existing female deficit.

The severity of the older missing women phenomenon in countries where it follows a life-course explanation (Afghanistan, Bangladesh, Bhutan, India, and Pakistan) may have adverse consequences for the population as a whole that could be magnified in future generations. The literature on China and India already details the consequences for women of a surplus of young men of marriageable age who are unable to find wives: social victimisation, sexual slavery, forced prostitution, kidnapping, and forced marriage migrations (Kaur 2004; Ebenstein, Sharygin 2009; Trent 2015). Such consequences are likely to be magnified in each subsequent age category due to their potential spill-over effects on preceding age categories. For example, the female deficit in young adulthood in China precipitated an indelible spill-over effect by creating missed opportunities for a union between men and the missing women, thereby depressing fertility rates (Attané 2006). At the older stage, the persistent shortage of women has the potential to increase male rates of widowhood, thereby not only multiplying the problem of forced marriage but also exacerbating the quality of life of daughters and daughters-in-law who provide caregiving services (Ezdi,

\footnotetext{
${ }^{4}$ The UCDP/PRIO armed conflicts database classifies the intensity of a conflict (by death toll) into two categories: category 1 includes a death toll between 25 and 9999; category 3 includes a death toll of 1000 or more (Gleditsch et al. 2002; Petterson, Eck 2018).

${ }^{5}$ For the 21 conflicts recorded for Bangladesh, the death toll per conflict is less than 1000 deaths/conflict.
} 
Künemund 2019). In this way, the surplus of older men is likely to shift the work of caring for older people from the family to the society, further precipitating the breakdown of traditional norms and intensifying the already existing pressure on economic and social institutions to cater to rapidly ageing populations in South Asia.

Given the negative social consequences of the older missing women phenomenon, immediate remedial action is necessary to rectify the female deficit where it occurs. Possible courses of action include social pensions and legislative change. Such measures may result in financial independence in old age; elevating the position of women in society and changing gender norms (Chung, Das Gupta 2007; Vlachantoni, Falkingham 2013). It is yet to be seen, however, if such changes will be sufficient to reverse the female deficit across multiple life domains in the worst affected countries.

\section{Conclusion}

This paper uses a theoretical framework (Figure 1) to examine the (older) missing women phenomenon and uses the example of South Asia to apply this framework. It explored the potential causal mechanisms, ones not restricted to South Asia or the older life stage, behind the (older) missing women phenomenon (Figure 2 and discussion).

The results for some of the South Asian countries are not very surprising in terms of missing women in their total population: Pakistan, India, and Bangladesh have already been discussed in the literature as having missing women in their total population, and Anderson and Ray (2012) have discussed the existence of missing women in the older population in India. However, the presence of a female deficit, especially in the older age groups, in the remaining countries, i.e. Afghanistan, Bhutan, Iran, Nepal, and Maldives, is mostly undocumented.

The results of this paper reveal that although most of the missing women literature has concentrated on explanations of the phenomenon that occur at the time of birth and during childhood, a substantial female deficit persists in the older (60+) population of all South Asian countries except Sri Lanka. It also highlights the gendered nature of conflicts and natural disasters, and their role in contributing to the (older) missing women phenomenon. Although the same results are found when immigrants are included and excluded, the analysis clearly shows the importance of taking migration into account when estimating the scale of the missing women problem.

Although the investigation here focused on South Asia, the results of this paper have universal applicability for three reasons. First, the (older) missing women phenomenon is an extreme manifestation of a gender bias that persists on some level in most countries in the world. A cursory glance at Figure 2 may shed some light on this: for example, rural-urban differences may in most countries predispose 
older women in rural settings to violence; natural disasters may have more adverse consequences for women than for men worldwide. Second, the paper sheds light on how migrant (including refugee) inflows and outflows affect the demographic composition of the population. Migration flows dominated by a specific gender create strong imbalances in the sending and receiving countries and may provide an opportunity for receiving countries with an ageing population to rectify their demographic problems. Third, the concept of missing women is no longer restricted to a few countries in Asia and Africa. Over the past decade, substantial literature has shown the pervasiveness of the missing women phenomenon among Asian and, to a lesser extent, African immigrant communities in Europe and North America (e.g. Almond, Edlund, Milligan 2013; Mussino, Miranda, Ma 2018). Understanding the age distribution of the phenomenon at different life stages in the country of origin is therefore a first step in understanding its pervasiveness in immigrant communities.

The (older) missing women phenomenon is an extreme manifestation of gender bias. Figure 1 shows how easily it can be adapted to fit any country in the world. Figure 2 provides a non-exhaustive list of the mechanisms that drive it. The example of South Asia uses numbers to not only express a theory but also to quantify the human cost of gender discrimination. The investigated countries show a cluster of factors and intermediary forces that are responsible for missing women and that are present to some extent worldwide, which makes it possible to measure the true impact of these factors and forces on women. The present analysis should therefore be used to monitor gender roles and discrimination worldwide.

\section{References}

Abel, G. J., N. Sander. 2014. Quantifying Global International Migration Flows. Science 343 (6178): 1520-1522, https://doi.org/10.1126/science.1248676.

Almond, D., L. Edlund, K. Milligan. 2013. Son Preference and the Persistence of Culture:

Evidence from South and East Asian Immigrants to Canada. Population and Development Review 39 (1): 75-95, https://doi.org/10.1111/j.1728-4457.2013.00574.x.

Anderson, S., D. Ray. 2010. Missing Women: Age and Disease. Review of Economic Studies 77 (4): 1262-1300, https://doi.org/10.1111/j.1467- 937X.2010.00609.x.

Anderson, S., D. Ray. 2012. The Age Distribution of Missing Women in India. Economic and Political Weekly 47 (47/48): 87-95.

Attané, I. 2006. The Demographic Impact of a Female Deficit in China, 2000-2050.

Population and Development Review 32(4): 755-770, https://www.jstor.org/ stable/20058926.

Barford, A., D. Dorling, G. Smith, M. Shaw. 2006. Life Expectancy: Women Now on Top Everywhere. BMJ 332 (7545): 808, https://doi.org/10.1136/bmj.332.7545.808.

Bartlett, L. A., S. Mawji, S. Whitehead, C. Crouse, S. Dalil, D. Ionete, P. Salama. 2005. 


\section{NV STATI / ARTICLES}

Where Giving Birth is a Forecast of Death: Maternal Mortality in Four Districts of Afghanistan, 1999-2002. The Lancet 365 (9462): 864-870, https://doi.org/10.1016/ S0140-6736(05)71044-8.

Bennett, R., A. Zaidi. 2016. Ageing and Development: Putting Gender Back on the Agenda. International Journal on Ageing in Developing Countries 1 (1): 5-19.

Bongaarts, J., C. Z. Guilmoto. 2015. How Many More Missing Women? Excess Female Mortality and Prenatal Sex Selection, 1970-2050. Population and Development Review 41 (2): 241-269, https://doi.org/10.1111/j.1728-4457.2015.00046.x.

Borooah, V., S. Iyer. 2004. Religion and Fertility in India: The Role of Son Preference and Daughter Aversion. Apollo-University of Cambridge Repository, https://doi.org/10.17863/ cam.5410.

Cainkar, L. 2013. Global Arab World Migrations and Diasporas. Arab Studies Journal 21 (1): 126-165.

Chung, W., M. Das Gupta. 2007. The Decline of Son Preference in South Korea: The Roles of Development and Public Policy. Population and Development Review 33 (4): 757-783, https://doi.org/10.1111/j.1728-4457.2007.00196.x.

Coale, A. J. 1991. Excess Female Mortality and the Balance of the Sexes in the Population: An Estimate of the Number of 'Missing Females'. Population and Development Review 17 (3): 517-523, https://doi.org/10.2307/1971953.

Coleman, J. S. 1986. Social Theory, Social Research, and a Theory of Action. American Journal of Sociology 91 (6): 1309-1335, https://doi.org/10.1086/228423.

Dannefer, D. 2003. Cumulative Advantage/Disadvantage and the Life Course: CrossFertilizing Age and Social Science Theory. The Journals of Gerontology: Series $B 58$ (6): S327-S337, https://doi.org/10.1093/geronb/58.6.S327.

Das Gupta, M. 1987. Selective Discrimination against Female Children in Rural Punjab, India. Population and Development Review 13 (1): 77, https://doi.org/10.2307/1972121.

Das Gupta, M., P. N. Mari Bhat. 1997. Fertility Decline and Increased Manifestation of Sex Bias in India. Population Studies 51 (3): 307-315, https://doi.org/10.1080/003247203100 0150076.

Das Gupta, M., L. Shuzhuo. 1999. Gender Bias in China, South Korea and India 1920-1990: Effects of War, Famine and Fertility Decline. Development and Change 30 (3): 619-652, https://doi.org/10.1111/1467-7660.00131.

Davidson, P. M., M. DiGiacomo, S. J. McGrath. 2011. The Feminization of Aging: How Will This Impact on Health Outcomes and Services? Health Care for Women International 32 (12): 1031-1045, https://doi.org/10.1080/07399332.2011.610539.

Drèze, J., P. V. Srinivasan. 1997. Widowhood and Poverty in Rural India: Some Inferences from Household Survey Data. Journal of Development Economics 54 (2): 217-234, https://doi.org/10.1016/S0304-3878(97)00041-2.

Ebenstein, A. Y., E. J. Sharygin. 2009. The Consequences of the 'Missing Girls' of China.

The World Bank Economic Review 23 (3): 399-425, https://doi.org/10.1093/wber/lhp012.

Elder, G. H. 1994. Time, Human Agency, and Social Change: Perspectives on the Life Course. Social Psychology Quarterly 57 (1): 4-15, https://doi.org/10.2307/2786971.

Ezdi, S., H. Künemund. 2019. Sex Ratios in Old Age: Comparing Countries in Middle Eastern 
Asia to East and Southeast Asia. Pp. 137-159 in Anson, J. A., W. Bartl, A. Kulczycki (eds.). Studies in the Sociology of Population. Cham: Springer, https://doi.org/10.1007/978-3319-94869-0_6.

Fargues, P. 2006. International Migration in the Arab Region: Trends and Policies. Beirut: United Nations Population Division.

Ferraro, K. F., T. P. Shippee. 2009. Aging and Cumulative Inequality: How Does Inequality Get Under the Skin? The Gerontologist 49 (3): 333-343, https://doi.org/10.1093/geront/ gnp034.

Garenne, M. 2009. Sex Ratio at Birth and Family Composition in Sub-Saharan Africa: InterCouple Variations. Journal of Biosocial Science 41: 399-407.

Ghobarah, H. A., P. Huth, B. Russett. 2003. Civil Wars Kill and Maim People - Long after the Shooting Stops. American Political Science Review 97 (2): 189-202, https://doi. org/10.1017/S0003055403000613.

Gibson, D. 1996. Broken down by Age and Gender: 'The Problem of Old Women' Redefined. Gender and Society 10 (4): 433-448.

Gledistch, N. P., P. Wallensteen, M. Erikkson, M. Sollenberg, H. Strand. 2002. Armed Conflict 1946-2001: A New Dataset. Journal of Peace Research 39 (5).

Guha-Sapir, D., R. Below, P. Hoyois. 2016. EM-DAT: The CRED/OFDA International Disaster Database. Brussels: Université Catholique de Louvain. Retrieved 15/05/2016 (www. emdat.be).

Guilmoto, C. Z. 2009. The Sex Ratio Transition in Asia. Population and Development Review 35 (3): 519-549, https://doi.org/10.1111/j.1728-4457.2009.00295.x.

Hazzard, W. R., D. Applebaum-Bowden. 1990. Why Women Live Longer Than Men: The Biologic Mechanism of the Sex Differential in Longevity. Transactions of the American Clinical and Climatological Association 101: 168-189, PMID: 2486441.

International Labour Organisation (ed.). 2014. Gender and Migration from Bangladesh: Mainstreaming Migration into the National Development Plans from a Gender Perspective. Dhaka: ILO.

Kaur, R. 2004. Across-Region Marriages: Poverty, Female Migration and the Sex Ratio. Economic and Political Weekly 39 (25): 2595-2603.

Klasen, S. 1994. 'Missing Women' Reconsidered. World Development 22 (7): 1061-1071, https://doi.org/10.1016/0305-750X(94)90148-1.

Klasen, S., C. Wink. 2003. 'Missing Women': Revisiting the Debate. Feminist Economics 9 (2-3): 263-299, https://doi.org/10.1080/1354570022000077999.

Komp, K., S. Johansson. 2016. Population Ageing in a Lifecourse Perspective: Developing a Conceptual Framework. Ageing \& Society 36 (9): 1937-1960, https://doi.org/10.1017/ S0144686X15000756.

Li, Q., M. Wen. 2005. The Immediate and Lingering Effects of Armed Conflict on Adult Mortality: A Time-Series Cross-National Analysis. Journal of Peace Research 42 (4): 471492, https://doi.org/10.1177/0022343305054092.

Manchanda, S., B. Saikia, N. Gupta, S. Chowdhary, J. M. Puliyel. 2011. Sex Ratio at Birth in India, Its Relation to Birth Order, Sex of Previous Children and Use of Indigenous Medicine. PLOS ONE 6 (6): e20097, https://doi.org/10.1371/journal.pone.0020097. 


\section{NV STATI / ARTICLES}

Mayer, K. U. 2004. Whose Lives? How History, Societies, and Institutions Define and Shape Life Courses. Research in Human Development 1 (3): 161-187, https://doi.org/10.1207/ s15427617rhd0103_3.

Mayer, K. U., A. Goedicke, M. Diewald, M. 2006. After the Fall of the Wall: Life Courses in the Transformation of East Germany. Stanford, CA: Stanford University Press.

Mussino, E., V. Miranda, L. Ma. 2018. Changes in Sex Ratio at Birth among Immigrant Groups in Sweden. Genus 74 (13): 1-15, https://doi.org/10.1186/s41118-018-0036-8.

Neugarten, B. L., N. Datan. 1973. Sociological Perspectives on the Life Cycle. Pp. 53-69 in Baltes, P., K. W. Schaie (eds.). Life-Span Developmental Psychology: Personality and Socialization. New York: Academic Press, https://doi.org/10.1016/B978-0-12- 0771509.50009-5.

Neumayer, E., T. Plümper. 2007. The Gendered Nature of Natural Disasters: The Impact of Catastrophic Events on the Gender Gap in Life Expectancy, 1981-2002. Annals of the Association of American Geographers 97: 551-566, https://doi.org/10.1111/j.14678306.2007.00563.x.

O'Rand, A. M. 1996. The Precious and the Precocious: Understanding Cumulative Disadvantage and Cumulative Advantage Over the Life Course. The Gerontologist 36 (2): 230-238, https://doi.org/10.1093/geront/36.2.230.

Organization for Economic Cooperation and Development. 2006. Glossary of Statistical Terms. OECD Statistics Portal. Paris: OECD. Retrieved 15/1/2019 (https://stats.oecd.org/ glossary/).

Paolisso, M., J. Leslie. 1995. Meeting the Changing Health Needs of Women in Developing Countries. Social Science \& Medicine 40 (1): 55-65, https://doi.org/10.1016/02779536(94)00127-F.

Park, C. B., N. H. Cho. 1995. Consequences of Son Preference in a Low-Fertility Society: Imbalance of the Sex Ratio at Birth in Korea. Population and Development Review 21 (1): 59-84, https://doi.org/10.2307/2137413.

Peace, S., F. Dittman-Kohli., G. Westerhof, J. Bond. 2007. The Ageing World. Pp. 1-14 in Bond, J., S. Peace, F. Dittman-Kohli, G. Westerhof (eds.). Ageing in Society. Thousand Oaks, CA: SAGE.

Pew Research Center. 2012. 'Demographic Study, Buddhists.' Pew Research Center's Religion \& Public Life Project. Washington: Pew Research Center. Retrieved 15/1/2019 (https://www.pewforum.org).

Pettersson, T., K. Eck. 2018. Organized Violence, 1989-2019. Journal of Peace Research 55 (4), https://doi.org/10.1177/0022343320934986.

Plümper, T., E. Neumayer. 2006. The Unequal Burden of War: The Effect of Armed Conflict on the Gender Gap in Life Expectancy. International Organization 60: 723-754, https:// doi.org/10.1017/S0020818306060231.

Qureshi, K. 2012. Ageing: Gender, Social Class and Health in Pakistan. Lahore: Centre for Public Policy \& Governance. June 2014. (http://cppg.fccollege.edu.pk/ageing-gendersocial-class-and-health-in-pakistan/).

Ryder, N. B. 1965. The Cohort as a Concept in the Study of Social Change. American Sociological Review 30 (6): 843-861, https://doi.org/10.2307/2090964. 
Sanneving, L., N. Trygg, D. Saxena, D. Mavalankar, S. Thomsen. 2013. Inequity in India: The Case of Maternal and Reproductive Health. Global Health Action 6 (1): 19145, https://doi. org/10.3402/gha.v6i0.19145.

Sen, A. 1990. More Than 100 Million Women Are Missing. The New York Review of Books 37 (20): 61-66.

Sen, A. 1992. Missing Women. BMJ 304 (6827): 587-588, https://doi.org/10.1136/ bmj.304.6827.587.

Settersten, R. A., K. U. Mayer. 1997. The Measurement of Age, Age Structuring, and the Life Course. Annual Review of Sociology 23 (1): 233-261, https://doi.org/10.1146/ annurev.soc.23.1.233.

Simkhada, P., E. van Teijlingen, M. Gurung, S. P. Wasti. 2018. A Survey of Health Problems of Nepalese Female Migrants Workers in the Middle-East and Malaysia. BMC International Health and Human Rights 18 (1), https://doi.org/10.1186/s12914- 018-0145-7.

Thimothy, R., S. K. Sasikumar. 2012. Migration of Women Workers from South Asia to the Gulf. New Delhi: V. V. Giri National Labour Institute, NOIDA and UN Women.

Trent, K., J. S. South, S. Bose. 2015. The Consequences of India's Male Surplus for Women's Partnering and Sexual Experiences. Journal of Family Issues 36 (8): 1062-1086, https:// doi.org/10.1177/0192513X13499760.

UNESCAP. 2010. Situation Report International Migration in South and South-West Asia. Bangkok: UNESCAP. Retrieved 15/02/2017 (https://sitreport.unescapsdd.org/)

United Nations, Department of Economic and Social Affairs. 2015a. World Population Ageing 2015: Highlights. New York. United Nations Department of Economic and Social Affairs.

United Nations, Department of Economic and Social Affairs, Population Division. 2015b. World Population Prospects: The 2015 Revision, Methodology of the United Nations Population Estimates and Projections. Working Paper No. ESA/P/WP. 242. New York: United Nations.

United Nations, Department of Economic and Social Affairs, Population Division. 2017. World Population Prospects: The 2017 Revision, custom data acquired via website. New York: United Nations. Retrieved 30/05/2018 (https://population.un.org).

United Nations, Department of Economic and Social Affairs. 2015. Trends in International Migrant Stock: Migrants by Age and Sex (United Nations database, POP/DB/MIG/Stock/ Rev.2015). New York: United Nations. Retrieved 30/05/2018 (https://population.un.org) United Nations, Department of Economic and Social Affairs. 2017. International Migration Report 2017 (No. ST/ESA/SER.A/403). United Nations Department of Economic and Social Affairs Population Division. New York: United Nations.

United Nations 2010. The United Nations Terminology Database. New York: United Nations. Retrieved 01/01/2009 (https://unterm.un.org/unterm).

Vlachantoni, A., J. Falkingham. 2013. Gender and Old-Age Pension Protection in Asia (No. 209). Brasilia: International Policy Centre for Inclusive Growth.

Véron, J. 2008. La démographie de l'Asie du Sud des années 1950 aux années 2000: Synthèse des changements et bilan statistique. Population 63 (1): 9, https://doi. org/10.3917/popu.801.0009. 
Wickramasekara, P. 2011. Labour Migration in South Asia: A Review of Issues, policies and practices (No.108). Geneva. International Labour Office.

Zaman, H. 1999. Violence Against Women in Bangladesh. Women's Studies International Forum 22 (1): 37-48, https://doi.org/10.1016/S0277-5395(98)00093-4.

Zhu, W. X., L. Lu, T. Hesketh. 2009. China's Excess Males, Sex Selective Abortion, and One Child Policy: Analysis of Data from 2005 National Intercensus Survey. BMJ 338 (2): b1211-b1211, https://doi.org/10.1136/bmj.b1211.

(a) BY-NC Sehar Ezdi, 2021.

(a) BY-NC Institute of Sociology of the Czech Academy of Sciences, 2021.

Sehar Ezdi is a postdoctoral researcher at INSERM (Maintain Aging Research team, CERPOP, Université de Toulouse, Inserm, Université Paul Sabatier) in Toulouse, France. Prior to this she worked as a postdoctoral researcher at the Centre Maurice Halbwachs (ENS, CNRS, EHESS) in Paris, and as a senior researcher (ERC project) at the University of Turku, Finland. The current article is an excerpt from her PhD thesis, which she completed at the University of Vechta, Germany, in 2017. Contact e-mail: sehar.ezdi@inserm.fr, seharezdi@gmail.com. 